\title{
A PRIVATIZAÇÃO DO SISTEMA CARCERÁRIO NO BRASIL
}

\author{
Cleyton Heleno Pereira da Silva, Danielle Yurie Moura da Silva
}

Universidade do Oeste Paulista - UNOESTE, curso de Direito, Presidente Prudente, SP. E-mail: danyurie25@gmail.com

\section{RESUMO}

O presente artigo tem por objetivo analisar a crise que afeta o sistema penitenciário nacional nos últimos tempos, neste sentindo reflete-se este requer urgentemente o estudo e adoção de novas alternativas para o cumprimento das pena de prisão. A ideia de privatização dos presídios é uma destas alternativas que é uma proposta nova tanto no Brasil como no mundo. Diversos países já adotaram tal modelo, onde notadamente tem se conseguido ótimos resultados. Alguns entendem que a privatização não resolveria o problema, pelo contrário, em um sistema que vise lucro, a ganância poderá conduzir à clientela cada vez maior, com sacrifício evidente dos direitos fundamentais. A metodologia a se adotada consistirá na pesquisa bibliográfica, com a utilização de doutrina, jurisprudência e artigos eletrônicos entre outros. Conclui-se que essa medida pode representar uma resposta à crise que enfrentamos.

Palavras-chaves: Direito Penal - Execução Penal - Sistema Carcerário - Privatização.

\section{THE PRIVATIZATION OF THE CARCERARY SYSTEM IN BRAZIL}

\begin{abstract}
This article aims to analyze the crisis that affects the national prison system in recent times, in this feeling is reflected that urgently requires the study and adoption of new alternatives for the enforcement of prison sentences. The idea of privatizing prisons is one of these alternatives, which is a new proposal both in Brazil and in the world. A number of countries have already adopted such a model, notably where excellent results have been achieved. Some people believe that privatization would not solve the problem; on the contrary, in a profit-oriented system, greed could lead to a growing clientele, with obvious sacrifice of fundamental rights. This measure may represent a response to the crisis we face.
\end{abstract}

Keywords: Criminal Law - Criminal Execution - Prison System - Privatization.

\section{INTRODUÇÃO}

O sistema penitenciário brasileiro está em crise. A ocorrência semanal de rebeliões e incidentes violentos indica que as prisões e delegacias não estão sendo administradas de modo eficiente e que as autoridades não exercem controle total sobre essas instituições penais.

Este trabalho ressalta de forma comparativa alguns modelos penitenciários existentes em outros países.

As principais causas de falência do sistema penitenciário brasileiro são: superlotações dos presídios; falta de reeducação do detento; falta de profissionalização do preso; falta de assistência ao egresso; falta de funcionários especializados; corrupção carcerária; falta de separação dos reeducados por grau de periculosidade, falta de recursos nos presídios, reincidência, falta de melhor remuneração para os funcionários, e principalmente, falta de presídios.

Os presos cumprem suas penas em condições de superlotação e falta de higiene nas carceragens das delegacias, sua transferência para penitenciária muitas vezes é adiada devido à falta de espaço, inércia da justiça ou corrupção. As condições de detenção existentes em 
numerosas prisões e delegacias brasileiras são pavorosas e equivalem a formas cruéis, desumanas e degradantes de tratamento e punição.

Além disso, correm o risco de contrair doenças potencialmente fatais, como a tuberculose e a AIDS, e os presos afetados não recebem tratamento devido.

Atualmente, as prisões não recuperam ninguém, pelo contrário, corrompe ainda mais o condenado. O ruim se torna ainda pior.

A situação é tão alarmante e degradante que os presídios ou as penitenciárias são rotuladas com expressões como: sucursais do inferno, universidades do crime e depósitos de seres humanos.

O encarceramento puro e simples não apresenta condições para a harmônica integração social do condenado, como preconizado na Lei de Execução Penal (Lei n 7.210, de 11.07.1984).

Punir, encarcerar e vigiar não é o bastante, é necessário que se conceda à pessoa de quem o Estado retirou o direito à liberdade o acesso a meios e formas de sobrevivência que lhe proporcionem as condições de que precisa para reabilitar-se moral e socialmente.

Sendo isso, o objetivo deste estudo é mostrar uma alternativa de penitenciárias que podem ser a solução de um problema que tem prejudicado a sociedade como um todo.

\section{HISTÓRICO DAS PRISÕES NO BRASIL}

Para se compreender o sistema atual de prisões é imprescindível reporta-se aos períodos que antecederam a atual legislação.

No Brasil, a princípio, os acusados permaneciam temporariamente à espera da condenação. Essa situação perdurou, passando pelas Ordenações Afonsinas, Manuelinas e Filipinas, acrescidas das leis extravagantes, baseando-se na brutalidade das sanções corporais e na abundância absurda de ilícitos, até a introdução do Código Criminal do Império do Brasil, em 16 de dezembro de 1830, sancionado por D. Pedro I. Código Criminal do Império reduzia a quantidade para somente três infrações: insurreição de escravos, homicídio agravado e latrocínio.

O Código do Império foi o reflexo, no Brasil, das profundas modificações ocorrentes na Europa, projetadas pelas novas correntes de pensamento. Com a Abolição da Escravidão, em 1888, e a Proclamação da República, em 1889, realizam-se sensíveis mudanças no Código Penal. 0 novo Código, de 1890, previa as seguintes modalidades: prisão celular; reclusão; prisão com trabalho obrigatório; prisão disciplinar. Cada uma cumprida num estabelecimento específico.

No entanto os estabelecimentos já se encontravam em péssimas condições, baseado em visitas aos principais presídios do país.

Conforme FALCONI preconiza:

(...) neste momento, o sistema presidial abarca três modalidades de prisão: a correcional ou policial, que é a detestável Prisão Temporária, a prisão processual, que se realiza via prisão em flagrante e prisão preventiva, e a prisão judicial, que é a própria condenação, indiferente se com ou sem trânsito em julgado. (FALCONI, 1998, p.64).

Porém, devido à precária situação dos estabelecimentos, todos os presos se misturavam no mesmo espaça físico, não possibilitando a distinção entre o preso correcional, o processual e o condenado.

Em 1932, devido à dificuldade de aplicação e até de conhecimento das inúmeras leis extravagantes existentes, é promulgado o Decreto 22.213 de 14 de dezembro, o qual promovia a consolidação das leis penais.

Em 31 de dezembro de 1940 é publicado o novo Código Penal (Decreto lei 2.848 de 7 de dezembro de 1940) através do qual as penas foram simplificadas em duas categorias: principais, 
que se subdividiam em reclusão e detenção (que são as espécies da pena privativa de liberdade) e multa; e as penas acessórias, que se subdividiam em perda de função, interdição de direitos e publicação das sentenças.

Desde então, muitos avanços ocorreram na legislação, relacionados à proteção do indivíduo, moderando o poder punitivo do Estado. Porém, pouco se buscou como alternativa à pena de prisão. O nosso Código Penal vem mantendo-a como principal forma de punição e defesa da sociedade.

Percebe-se que desde o início o sistema penitenciário brasileiro não recupera ninguém, ao lado da enorme carência de vagas nos estabelecimentos já existentes, torna-se de extrema importância o aparecimento de novas alternativas a fim de solucionar este grave problema social. É dentro deste contexto que surgiu o fenômeno privatização do sistema carcerário, hoje em dia, já adotado em diversos países. Essa ideia é nova no Brasil, como também no mundo, pois somente há aproximadamente 10 anos é que se criaram os chamados presídios privados.

A apresentação da ideia que chama a iniciativa privada a cooperar com o Estado na fase da execução penal tem se revelado um assunto muito polêmico no mundo jurídico.

A chamada privatização dos presídios é uma denominação inadequada, pois não se trata de vender em Bolsa ações dos estabelecimentos prisionais, mas tão somente chamar e admitir a participação da sociedade, da iniciativa privada, que viria colaborar com o Estado nessa importante e arriscada função que é a de gerir nossas unidades prisionais, vez que a gestão privada poderia oferecer soluções onde a burocracia estatal tem demonstrado sua total ineficácia.

\section{OBSTÁCULOS À PROPOSTA DE PRIVATIZAÇÃO DO SISTEMA PENITENCIÁRIO BRASILEIRO}

Sob o ponto de vista ético, seria inaceitável que um indivíduo, além de exercer domínio sobre outro, vise apenas o lucro do trabalho carcerário, pois a ganância poderá conduzir à clientela cada vez maior, com sacrifício evidente dos direitos humanos.

Segundo SILVA e JUNIOR (2017) diz que:

A privatização, no caso, é a entrega ao particular de encargo público, ou seja, privatizar é entregar este serviço público para ser executado por terceiros, mediante uma compensação financeira e, a partir daí o Poder público continua com o seu poder normativo, fiscalizador, complementador e de intervenção, quando razões de ordem pública determinarem.

Privatização das Prisões, este princípio ético está consagrado nas Regras Mínimas para o Tratamento dos Reclusos, estabelecidas pela Organização das Nações Unidas em 1955.

As regras referidas determinam que o trabalho penitenciário, embora obrigatório, não deverá ter caráter aflitivo (Regra 71.1) e que a organização do trabalho penitenciário deverá assemelhar-se o mais possível ao que se aplicam a um trabalho similar fora do estabelecimento (Regra 72.1).

O respeito aos preceitos da ONU (Organizações das Nações Unidas) é tradicional no Brasil, assim como, é tradicional, também, o respeito aos preceitos éticos, em matéria de trabalho prisional.

Portanto, sob o ponto de vista ético, seria intolerável enriquecer sobre a base do quantum de castigo que seja capaz de infligir a um condenado.

Sob o ponto de vista jurídico, a execução penal sempre pretendeu ser uma atividade jurisdicional. Atualmente, com a Lei de Execução Penal (Lei n 7.210 de 11/07/84), o caráter jurisdicional e processual da execução ficou perfeitamente marcado.

Daí decorre que a administração penitenciária faz parte da atividade jurisdicional do Estado sendo indelegável. 
A Lei de Execução Penal, além de proibir que o trabalho carcerário seja gerenciado por empresas privadas, veda, também a delegação da gestão penitenciária aos particulares.

O princípio da jurisdição única atribui ao Estado o monopólio da imposição e da execução de penas ou outras sanções. Inconcebível seria que o Estado executasse a tutela jurisdicional, representado por autoridade que não se reveste de poderes suficientes para tanto. O Estado não está legitimado para transferir a uma pessoa física ou jurídica, o poder de coação de que está investido e que é exclusivamente seu, visto que a violação de indelegabilidade da atividade jurisdicional importa em inconstitucionalidade.

E por fim, no âmbito político, privatizar prisões significa consagrar um modelo penitenciário violador dos direitos fundamentais do homem.

Com o antigo liberalismo político preconizado por Adam Smith, mesmo com todo estímulo à participação privada na vida econômica, jamais colocou em dúvida o monopólio do Estado, com referência às atividades de segurança pública, administração da justiça e defesa nacional. Transferir essas atividades aos particulares seria negar existência ao próprio órgão político, seria desvirtuar-lhe o seu ser, o seu próprio significado.

Pelos motivos acima expostos, a proposta de privatização dos presídios, além de ofender os modernos princípios da política criminal humanista, é imoral, ilegal, e só serviria para encher os cofres das empresas privadas.

O objetivo teórico da administração penitenciária é combater a criminalidade, e não, obter lucros; ora, as empresas que desejam participar da administração penitenciária visam obter lucros e retirar esse lucro da própria existência da criminalidade; logo, tais empresas não iriam lutar contra a criminalidade, e se não tem tal interesse, não devem administrar prisões.

\section{FORMAS DE TERCEIRIZAÇÃO DA ATIVIDADE PENITENCIÁRIA}

Não se pode negar que o Brasil, nos últimos anos, vem adotando um modelo gerencial. Ou seja, a Administração Pública começa a se despir da posição de prestadora de serviços, desestatizando-os, passando, então, a gerenciar a sua prestação, fiscalizando e controlando atividades transferidas à terceiro, dentro das políticas públicas previamente estabelecidas pelo Estado, conforme relata TOURINHO (2017).

Segundo ele, argumenta-se favoravelmente ao tema, a falência do sistema carcerário no Brasil. Não cabe neste trabalho abordar as razões de tal fracasso. No entanto, torna-se claro que a falta de vontade política aliada a enorme máquina burocrática do Estado, contribuem decisivamente para a construção da teoria em defesa da terceirização de presídios.

É necessário distinguir os diferentes tipos de participação das empresas privadas no setor carcerário

1. Uma companhia privada edifica, gerencia e comanda a prisão, recebendo os presos diretamente do Estado (privatização total pela empresa privada);

2. A companhia privada edifica a prisão e a aluga ao Estado que a gerirá com seu próprio pessoal;

3. Certos serviços na prisão são contratados com companhias privadas, tais como, fornecimento de alimentação, educação e assistência médica (a chamada terceirização);

4. Prisões-industriais em que o trabalho do preso passa a ser objeto do lucro das empresas particulares, tais estabelecimentos são construídos por empresários, ou os presos podem ser contratados para trabalhar em companhias vizinhas.

Estas são algumas das maneiras pelas quais as prisões privadas apresentam-se como possíveis soluções econômicas e eficientes aos graves problemas penitenciários que temos atravessado no Brasil. Trata-se de captar, explicar e criticar a emergência do discurso privatizante no campo prisional como ideologia, isto é, não como mera ficção ou ilusão, porém, antes como uma promessa, cujos termos e condições de possibilidade são possivelmente determinados, mas que ao mesmo tempo e contraditoriamente não pode ser realizada nestes mesmos termos, face 
ao grande número de obstáculos propostos que chegam até mesmo a declarar a inconstitucionalidade de tal medida.

No Brasil, seria inviável uma proposta de privatização total dos estabelecimentos prisionais, como acontece em alguns poucos Estados industrializados dos EUA, mas a ideia da privatização no Brasil poderia se tornar uma realidade aos poucos, através da terceirização, onde o Estado, ao contratar a execução do serviço ao setor privado, continuaria responsável por seu financiamento, regulação, avaliação e controle, mas se beneficiaria do acesso a novas tecnologias, redução dos gastos com pessoal, da burocracia, e dos atrasos nas construções de novos estabelecimentos.

Segundo RIBEIRO:

É preciso, sem nos iludirmos com a fata morgana da recuperação, assistir o preso e dar-lhe trabalho, necessário este ä autossuficiência dos presídios e reconhecido como dever social e requisito da dignidade humana, levandose em conta, em sua oferta, a habilitação, a condição penal e as necessidades futuras dos internos, assim como as oportunidades do mercado. É preciso discutir a ideia de privatização, implantável em projetos pilotos, em regime de gestão mista, e cujas vantagens, múltiplas, são de ordem humana, operacional, legal e financeira.

(RIBEIRO apud LEAL 2007, p. 02)

A adoção das prisões privadas tem sido em boa parte legitimada pelo argumento de que a introdução da competição e o emprego de técnicas e estratégias de gestão empresarial no sistema penitenciário permitiriam, simultaneamente, reduzir custos e aperfeiçoar os serviços.

O sistema prisional brasileiro é um dos piores do mundo. Segundo DAMÁSIO, em 1992 o Brasil tinha 114 mil pessoas presas. Em 1999, elas já eram 192 mil. E, nessa época, qual era o número de vagas no sistema penitenciário? Somente 107 mil. Hoje, nossos presos passam de 200 mil. Isso, evidentemente, sem falar em uma cifra que margeia os 300 mil mandados de prisão não cumpridos!

O setor privado desburocratizaria a gestão dos presídios, reduziria encargos trabalhistas; aos Estados estaria garantida a possibilidade de expandir e acelerar a política de construção de novos estabelecimentos; as empresas teriam mais agilidade e flexibilidade, o que se poderia comprovar a partir de algumas experiências de conversão de residências e hospitais desativados em estabelecimentos penitenciários. Tudo seria feito com o alívio do bolso do contribuinte e do governo ao mesmo tempo.

\section{CONSIDERAÇÕES}

A busca de soluções para o problema do Sistema Penitenciário Brasileiros e tornou emergencial. O sistema carcerário no Brasil é deteriorante e degradante, favorece o aprendizado de novas técnicas criminosas e cria seus próprios valores.

Em matéria de privatização, a experiência dos países estrangeiros pode nos servir de base, neste momento em que ideias reformadoras devem ser amoldadas. A privatização de nossos estabelecimentos penais pode representar uma resposta à crise que enfrentamos, mas tal medida, deveria ser colocada de forma gradativa. A participação privada poderia ocorrer na forma de fornecimento de certos serviços e bens para os presos (terceirização), desde que obedecidos os mandamentos legais referentes às licitações públicas.

Fácil se torna visualizar que para a efetivação de um programa que desse fim à falência do sistema carcerário brasileiro, seriam imprescindíveis estudos técnicos altamente especializados, encadeamento jurídico, dotações financeiras de grande porte e demais ações próprias de uma 
administração pública. Contudo, se não quisermos que o mundo desabe sobre nós, uma ligeireza na ação, nesse caso, é de importância fundamental.

Complementando a injustiça, o sistema punitivo, além de atuar seletivamente, promove a degradação da figura social do condenado, e, assim, não raras vezes, acaba por condicionar carreiras criminosas, em vez de preveni-las.

É dentro deste contexto que a proposta de privatização dos presídios deve ser analisada minuciosamente, vez que, através dela poderíamos minimizar os efeitos maléficos do cárcere, que ficaria restrito aos crimes de maior gravidade e aos condenados de alta periculosidade.

Nas prisões privadas, o trabalho do preso deve ser ponto de honra, onde todos os presos trabalhem, mas o resultado auferido pelo seu labor não poderia reverter em favor do empreendedor privado, destinando-se aos familiares do condenado e ao ressarcimento dos prejuízos que o condenado provocou.

E, mais, na verdade, não se estaria transferindo a função jurisdicional do Estado para o empreendedor privado, que cuidaria exclusivamente da função material da execução da pena. 0 administrador particular seria responsável pela comida, pela limpeza, pelas roupas, pela hotelaria enfim, por serviços que são indispensáveis num presídio.

A terceirização dos serviços penitenciários tem se revelado um modelo em franco desenvolvimento e deve ser expandido pelo resto do Brasil. O modelo de Guarapuava dá mostras de sucesso e há mais de um ano este mesmo sistema foi implantado na Penitenciária Regional do Cariri, e está funcionando perfeitamente.

Segundo a secretária nacional de justiça, as experiências nestes dois presídios comprovam que os presos reduziram seu tempo de pena e que a administração teve êxito.

O que não se pode admitir é afastar a experiência, pois nada que se possa substituir a prisão foi apresentado até agora e milhares de jovens estão apodrecendo em nossos cárceres, sem que a sociedade possa lhes ouvir a voz. Basta de tanta injustiça e indiferença em nossa sociedade.

\section{REFERÊNCIAS}

CAPEZ, Fernando. Lei de Execução Penal: artigo por artigo. São Paulo: Paloma Comercio de Apostilas, 1999.

DOTTI, René Ariel. Bases alternativas para o sistema de penas. 2. ed., São Paulo: Revista dos Tribunais, 1998.

FALCONI. FALCONI, Romeu. Sistema Presidial: Reinserção Social? São Paulo: Ícone Editora, 1998.

FRAGOSO, Heleno Cláudio. Lições de Direito Penal: Parte Geral. 10 ed., Rio de Janeiro: Forense, 1988 , vol. I.

MARTINS, Jorge Henrique Schaefer. Penas Alternativas. Curitiba: Juruá, 1999.

SILVA, Alessandra Priscila Moura e JUNIOR, Jorge J. de Araújo. Privatização pode ser a solução para a decadência do sistema penitenciário? Disponível em: http://www.direitonet.com.br/textos/x/52/55/525/DN Privatizacao_pode ser_a solucao_para_a decadencia do sistema penitenciario.doc Acesso em: 15.08.2017

TOURINHO, Rita Andréa Rehem Almeida. A terceirização do sistema carcerário no Brasil. Jus Navigandi, Teresina, ano 8 , n. 275, 8 abr. 2004. Disponível em: http://jus2.uol.com.br/doutrina/texto.asp?id=5055 . Acesso em: 26.08.2017. 